J. Lake Sci. (湖泊科学), 2012, 24(1): 123-128

http: //www.jlakes.org. E-mail : jlakes@niglas.ac.cn

(C) 2012 by Journal of Lake Sciences

\title{
太湖光合自养真核超微藻遗传多样性初探
}

谢薇薇 ${ }^{1,2}$, 王志伟 ${ }^{1}$, 孔繁翔 ${ }^{2}$, 史小丽 $^{2 * *}$

( 1 : 南京农业大学生命科学学院, 南京 210095)

(2: 中国科学院南京地理与湖泊研究所湖泊与环境国家重点实验室, 南京 210008)

摘 要: 采用真核藻类叶绿体 $16 \mathrm{~S}$ rRNA 的引物 PLA491F、OXY1313R, 通过 PCR、构建基因克隆库的方法初步调查了太湖 梅梁湾和东太湖光合自养真核超微藻的遗传多样性. 结果表明, 太湖自养型真核超微藻主要为隐藻 (Cryptophyta), 其次为 硅藻 (Bacillariophyta)、金藻 (Chrysophyta) 和定鞭藻 (Haptophyta). 该结果有助于我们更全面地了解太湖浮游藻类的群落 结构及生态功能.

关键词: 光合自养真核超微藻; 叶绿体 $16 \mathrm{~S} \mathrm{rRNA}$; 遗传多样性; 太湖

\section{Genetic diversity of photosynthetic picoeukaryotes in Lake Taihu}

XIE Weiwei ${ }^{1,2}$, WANG Zhiwei ${ }^{1}$, KONG Fanxiang ${ }^{2} \&$ SHI Xiaoli ${ }^{2}$

(1: College of Life Science, Nanjing Agricultural University, Nanjing 210095 , P. R. China)

(2: State Key Laboratory of Lake Science and Environment, Nanjing Institute of Geography and Limnology, Chinese Academy of Sciences, Nanjing 210008, P. R. China)

Abstract: Genetic diversity of photosynthetic picoeukaryotes has been investigated at two stations located in Meiliang Bay and East Taihu in Lake Taihu, respectively. Genetic libraries of chloroplast 16S rRNA gene have been constructed by using primer set PLA491F/OXY1313R, biased towards chloroplast of marine algae. The results show that most of photosynthetic picoeukaryotic sequences belong to Cryptophyta, and the rest of them are affiliated with Bacillariophyta, Chrysophyta and Haptophyta. The study can help us take knowledge of the community structure and ecological function of phytoplankton in Lake Taihu.

Keywords: Photosynthetic picoeukaryotes; chloroplast 16S rRNA gene; genetic diversity; Lake Taihu

光合自养型真核超微藻 (Photosynthetic Picoeukaryotes, PPEs) 为粒径小于 $2 \mu \mathrm{m}$ 的自养型真核原生生 物 ${ }^{[1]}$, 其广泛分布于海洋和淡水生态系统中, 作为重要的初级生产者, 在水生生态系统的物质循环和能量流 动中起着十分重要的作用. 尤其在热带、亚热带贫营养海域是重要的初级生产者, 对其所在海域的生物量贡 献巨大 ${ }^{[2]}$.

1994 年 $\mathrm{Li}$ 首次揭示了光合自养型真核超微藻由于具有较大的比表面积和高的碳吸收效率, 是海洋 初级生产力的重要贡献者 ${ }^{[3]}$. 国际上关于真核超微藻遗传多样性的调查和研究多集中于海洋, 近几年才 有少量关于湖泊的研究报道 ${ }^{[4-5]}$. 国内关于真核超微藻遗传多样性的研究才刚刚起步 ${ }^{[6]}$, 袁洁等 ${ }^{[7]}$ 构建了 我国南沙海域真核超微藻基因克隆库,发现了大量新型基因序列; 王建等 ${ }^{[8]}$ 对武汉东湖超微藻生态学进 行初步研究; 陈美军等 ${ }^{[9-11]}$ 对太湖不同湖区真核微型浮游生物基因多样性进行研究, 其中涉及部分微型 藻类.

调查真核超微藻多样性,一般将水样经过一定孔径的滤膜抽滤, 然后用真核生物 $18 \mathrm{~S}$ rRNA 基因的通用 引物扩增和克隆滤膜上的 DNA, 最后进行测序和序列比对、生物进化分析 ${ }^{[12]}$. 该方法得到的海洋和湖泊样 品的克隆库中,三分之二以上的基因序列属于异养真核微生物,但苂光原位杂交方法却发现, 在适宜藻类生

* 国家自然科学基金项目(31070420) 和国家重点基础研究发展计划 “973” 项目 (2008CB418005) 联合资助. 2011 02-04收稿;2011-05-19 收修改稿. 谢薇薇,女,1988 年生, 硕士研究生;E-mail:2010116093@ njau. edu. cn.

** 通信作者;E-mail: xlshi@ niglas. ac. cn. 
长的水环境中, 通常自养型真核超微藻相对异养真核微生物在数量上占绝对优势 ${ }^{[13]}$. 为了更好地揭示光合 自养型超微藻的遗传多样性, Fuller 等设计了针对真核藻类叶绿体 $16 \mathrm{~S} \mathrm{rRNA}$ 的引物来构建基因克隆库 ${ }^{[14]}$. 该引物能够特异性地扩增自养真核藻类, 较好地克服传统方法对异样真核微藻较高的扩增率.

本研究采用真核藻类叶绿体 $16 \mathrm{~S} \mathrm{rRNA}$ 的引物来构建基因克隆库, 以揭示太湖自养真核超微藻的遗传 多样性, 从而帮助我们更全面地了解湖泊浮游藻类的群落结构及生态功能, 同时为湖泊超微藻的研究和开 发利用提供一定的依据.

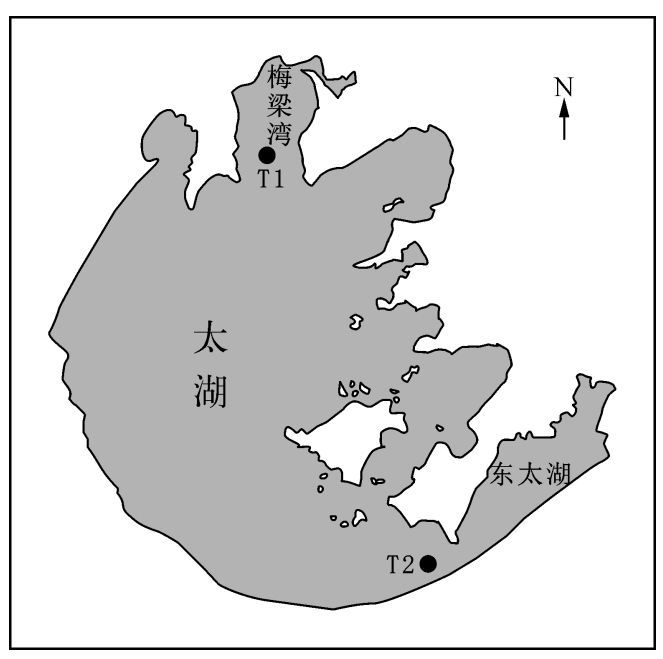

图 1 太湖采样点位置

Fig. 1 Location of sampling sites in Lake Taihu

\section{1 材料与方法}

\section{1 藻样采集}

梅梁湾位于太湖北部, 是目前太湖富营养化程度 最高的区域之一, 而东太湖的富营养水平在太湖几个 湖区中最低 ${ }^{[9]} .2010$ 年 3 月采集太湖梅梁湾 ( T1 点)、东太湖 ( $\mathrm{T} 2$ 点) 水样各 $500 \mathrm{ml}$ (图 1). 用 $20 \mu \mathrm{m}$ 的滤膜粗滤后分别用 $2 \mu \mathrm{m} 、 0.2 \mu \mathrm{m}$ 的滤膜逐级抽 滤, 得到粒径范围为 $0.2 \sim 2 \mu \mathrm{m}$ 的超微浮游藻类 ${ }^{[13]}$. 用 $10 \mathrm{ml}$ 离心管收集 $0.2 \mu \mathrm{m}$ 滤膜, 加 $3 \mathrm{ml}$ 细胞溶解 液, $-20^{\circ} \mathrm{C}$ 保存.

\section{2 藻样总 DNA 提取}

将加有细胞溶解液的离心管从 $-20^{\circ} \mathrm{C}$ 取出, 室 温溶解. 加人 $350 \mu \mathrm{l} 10 \%$ 的 SDS, $33.5 \mu \mathrm{l} 10 \mathrm{mg} / \mathrm{ml}$ 蛋白酶 $\mathrm{K}$, 混匀, $37^{\circ} \mathrm{C}$ 水浴 $50 \mathrm{~min}$ 后 $55^{\circ} \mathrm{C}$ 水浴 $20 \mathrm{~min}$, 期间每隔 $10 \mathrm{~min}$ 摇匀, 使反应充分. 加人等 体积的苯酚: 氯仿: 异戊醇 $(25: 24: 1)$ 抽提, 10000 转 $/ \mathrm{min} 、 4^{\circ} \mathrm{C}$ 下离心 $5 \mathrm{~min}$. 取上清至新离心管

中, 同样的方法再次抽提. 将上清转移至新离心管中, 加人等体积异丙醇和 0.4 倍体积的 $7.5 \mathrm{~mol} / \mathrm{L}$ 的醋酸 铵, 室温静置 $10 \mathrm{~min}$ 后, 10000 转 $/ \mathrm{min} 、 4^{\circ} \mathrm{C}$ 下离心 $30 \mathrm{~min}$. 弃溶液, 加人 $1 \mathrm{ml}$ 的 $70 \%$ 乙醇洗涤, 10000 转 $/ \min 、 4^{\circ} \mathrm{C}$ 下离心 $15 \mathrm{~min}$, 弃乙醇. 干燥 $30 \mathrm{~min}$, 使酒精充分挥发后, 每管加人 $30 \mu \mathrm{l}$ 的 $\mathrm{TE}$ 悬浮沉 淀, $-20^{\circ} \mathrm{C}$ 保存.

\subsection{PCR 反应与产物的纯化}

以上提取的藻样总 DNA 用于目的片段扩增. $50 \mu \mathrm{PCR}$ 反应液中含有 $25 \mathrm{mmol} / \mathrm{L} \mathrm{MgCl}_{2}, 2.5 \mathrm{mmol} / \mathrm{L}$ dNTP, $10 \times$ buffer, $5 \mathrm{U} / \mu \mathrm{l} \mathrm{Taq}$ DNA 聚合酶( TaKaRa 公司). 采用真核藻类 $16 \mathrm{~S}$ rRNA 基因的引物对 PLA

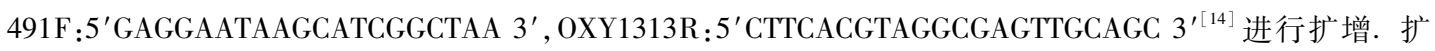
增反应程序: $95^{\circ} \mathrm{C}, 5 \mathrm{~min} ; 95^{\circ} \mathrm{C}, 1 \mathrm{~min} ; 55^{\circ} \mathrm{C}, 1 \mathrm{~min} ; 72^{\circ} \mathrm{C}, 1 \mathrm{~min}$,循环 30 次,最后 $72^{\circ} \mathrm{C}, 6 \mathrm{~min}$. 扩增完成后 用 $1 \%$ 琼脂糖凝胶电泳检测, 切取 PCR 产物目的片段(约 $822 \mathrm{bp}$ ), 用 Promega 公司的 PCR 纯化试剂盒( Wizard ${ }^{\circledR}$ SV Gel and PCR Clean-Up System) 进行纯化.

\section{4 克隆子篮选}

PCR 产物经纯化回收后与载体 pGEM-T Easy 连接, 并转化感受态大肠杆菌, 涂布于含有 Amp、IPTG 及 $\mathrm{X}$-gal 的 $\mathrm{LB}$ 培养平板上, 置于 $37^{\circ} \mathrm{C}$ 培养箱中倒置过夜. 在平板上挑取白斑单菌落转移至含有 $\mathrm{Amp}$ 的液体 LB 培养基中 $37^{\circ} \mathrm{C}, 150$ 转 $/ \min$ 振荡培养 $6 \sim 8 \mathrm{~h}$. 取 $1 \mu \mathrm{l}$ 菌液, 用 pGEM-T Easy 载体的通用引物 T7、SP6 扩增, 电 泳检测,对扩增出目的片段的菌液进行测序.

\section{5 序列分析}

将测序获得的序列剪切掉载体和引物区, 采用 Bellerophon 在线软件分析, 随后利用核苷酸序列进行分 子遗传多样性和分子系统学分析. 我们将核苷酸序列相似度为 $98 \%$ 的克隆定为属于同一 OTU, 代表相同 的属或种 ${ }^{[15]}$, 否则将被认为是不同的藻. 本研究共得到 14 个真核超微藻序列, Cluster 软件分析后发现 
有 10 个 OTU. 采用 MAFFT 5.8 软件 ( http://align. bmr. kyushu-u. ac. jp/mafft/online/server/) 对本研究得到的 10 个 OTU 和 34 个参考序列进行比对, Gblocks 软件剪切掉变异 较大的区域, Modeltest 软件计算得到针对该 44 个序列构建 进化树的最佳参数,最后用 PAUP 4. 0 构建 Neighbour Joining 生物进化树, 重复 1000 次得到 Bootstrap 值, 用 MEGA 4.1 软件对进化树进行编辑.

\section{2 结果与分析}

\subsection{DNA 的扩增与阳性克隆子}

篮选结果显示在 $822 \mathrm{bp}$ 左右有特异性的扩增片段条带,与 预期片段相符 (图 2). 目的片段纯化后直接与载体 pGEM-T Easy 连接转化获得数百个克隆, 最后每个样品挑出 46 个阳性 克隆进行测序.

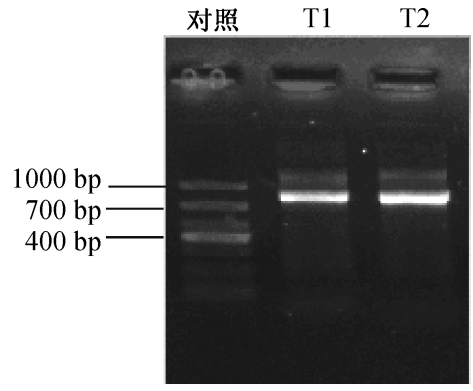

图 2 引物对 PLA491F 和 OXY1313R 对

$\mathrm{T} 1$ 和 $\mathrm{T} 2$ 点藻样总 DNA 的 PCR 扩增

Fig. 2 PCR amplifications of genomic DNA of $\mathrm{T} 1$ and $\mathrm{T} 2$ sites by primers PLA491F and OXY1313R

\section{$2.216 S$ rRNA 部分序列分析}

将得到的序列在 NCBI 上进行比较分析, 发现自养型真核超微藻优势种群为隐藻 (Cryptophyta), 占 $71.4 \%$, 其次是硅藻 (Bacillariophyta) 占 $14.3 \%$, 最后为金藻 (Chrysophyta) 和定鞭藻 ( Haptophyta), 分别占 7. $1 \%$ (表 1 ).

表 1 太湖 T1、T2 点自养超微藻 $16 \mathrm{~S}$ rRNA 克隆的序列分析

Tab. 1 Sequence analysis of the 16S rRNA of photosynthetic picoeukaryotes of T1 and T2 sites from Lake Taihu

\begin{tabular}{lllc}
\hline 克隆编号 & \multicolumn{1}{c}{ 最相似序列 } & 相似度/\% & Genebank 收录号 \\
\hline Taihu2010March T1.3 & Uncultured cryptophyte clone MC622-83 & 99 & EF052243 \\
Taihu2010March T1.10 & Uncultured haptophyte clone MAMA64-102 & 98 & EF051968 \\
Taihu2010March T1.13 & Cryptomonas curvata & 98 & AM709636 \\
Taihu2010March T1.18 & Asterionella ralfsii clone D4450 & 99 & EU580495 \\
Taihu2010March T1.25 & Uncultured cryptophyte clone MC622-53 & 98 & EF052214 \\
Taihu2010March T1.30 & Uncultured cryptophyte clone MC601-32 & 99 & EF051865 \\
Taihu2010March T1.34 & Uncultured cryptophyte clone MC622-53 & 98 & EF052214 \\
Taihu2010March T1.40 & Uncultured cryptophyte clone MC622-83 & 98 & EF052243 \\
Taihu2010March T1.41 & Uncultured cryptophyte clone MC615-67 & 99 & EF052138 \\
Taihu2010March T2.5 & Uncultured cryptophyte clone MAMA64-134 & 99 & EF051993 \\
Taihu2010March T2.18 & Uncultured cryptophyte clone MC601-131 & 99 & EF051924 \\
Taihu2010March T2.19 & Uncultured cryptophyte clone MC597-81 & 99 & EF051840 \\
Taihu2010March T2.38 & Uncultured diatom clone ST15-44D & 94 & DQ419429 \\
Taihu2010March T2.39 & Uncultured chrysophyte clone MC615-49 & 94 & EF052122 \\
\hline
\end{tabular}

构建 Neighbour Joining 生物进化树 (图 3). 与国内外研究结果比较, 确定了部分藻的具体分类, 但大部 分为未培养的藻类, 无法进行精确定位. 分析发现本研究中得到的金藻序列 EF052122、定鞭藻序列 EF051968 及隐藻序列如 EF052243、EF052214 等均与意大利 Naples 近海湾藻类亲缘性较近 ${ }^{[16]}$, 除金藻相似 度为 $96 \%$, 其他藻类的相似度均达到 98\% 99\% . 可见湖泊与海洋的藻类组成具有一定的相似性, 且隐藻等 广泛分布于海洋及淡水湖泊中. 硅藻序列 EU580495 与德国 Constance 湖及美国 Horsetooth 水库的硅藻相似 度较高 ${ }^{[17-18]}$, 说明硅藻在全球分布广泛, 且本研究发现的硅藻也多存在于湖泊中. 分析发现目前国际上关于 超微藻的研究也较少且相对集中,超微藻的已知种类较少. 此外在本研究的克隆文库中还发现了一些序列 


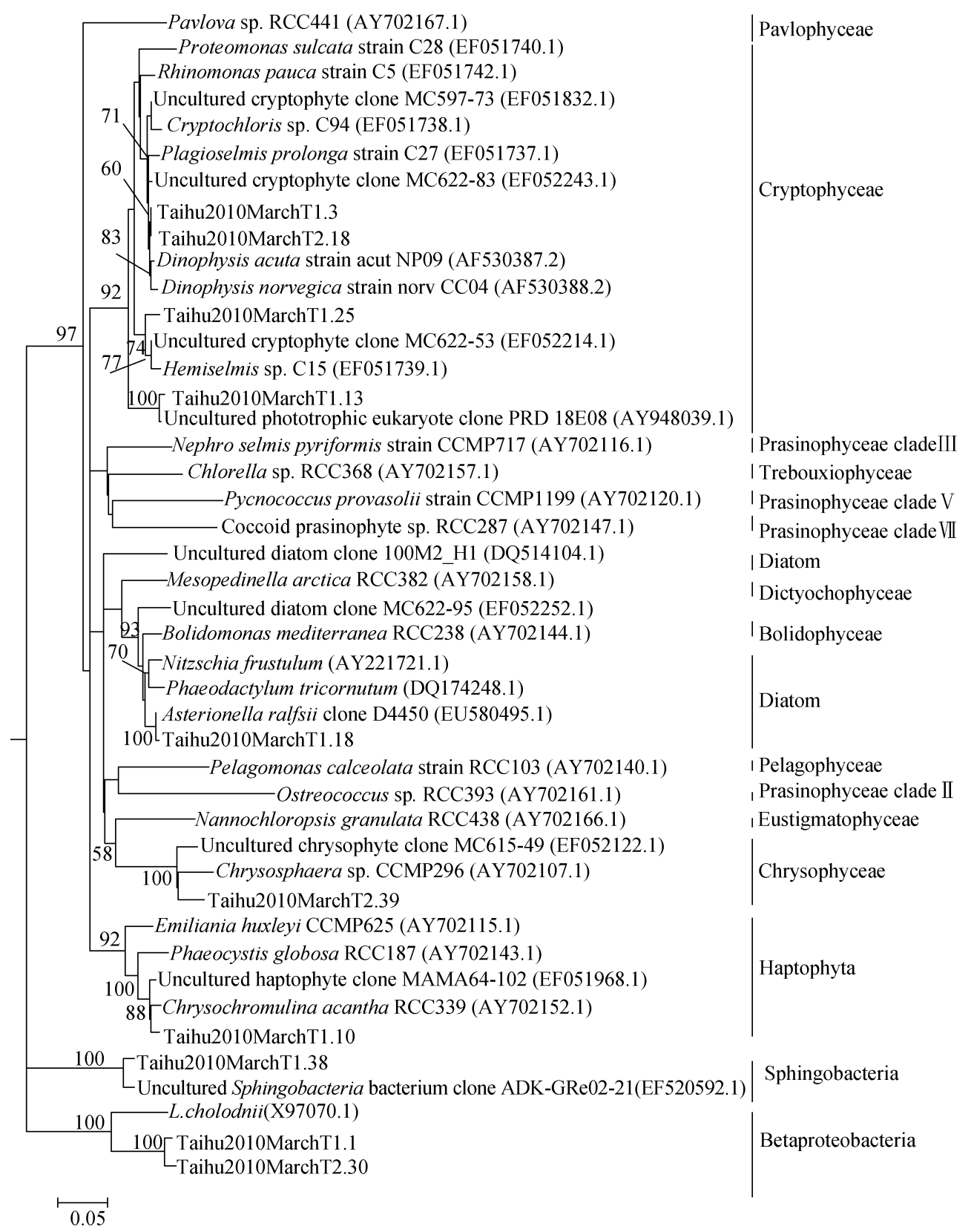

图 3 基于叶绿体 $16 \mathrm{~S}$ rRNA 的太湖真核超微藻系统发育学分析

Fig. 3 A chloroplast 16S rRNA phylogram of photosynthetic picoeukaryotes from Lake Taihu

属于光合细菌 (Betaproteobacteria) 和鞘氨醇杆菌 (Sphingobacteira).

\section{3 讨论}

\section{1 方法选择}

本研究采用了真核藻类 $16 \mathrm{~S} r R N A$ 基因的引物对 PLA491F、OXY1313 $\mathrm{R}^{[14]}$, 近年来该引物在海洋真核超 微藻研究中得到了广泛应用, 弥补了 $18 \mathrm{~S} \mathrm{rRNA}$ 通用引物构建的基因克隆库中大部分属于异养真核微生物 
而非自养真核藻类的不足,较好地反映了海洋真核超微藻的遗传多样性 ${ }^{[19-20]}$. 由于太湖富营养化程度高, 细 菌含量高, 实验中也扩增出部分光合细菌, 但目前国际分子生物学数据库中已有大量序列可进行比较, 因此 可有效排除光合细菌.

PCR 产物克隆法构建文库是研究超微型真核生物分子多样性的传统方法 ${ }^{[21-22]}$. Zuendorf 等对丹麦 Mariager 海峡样品进行克隆文库的构建, 对随机选取的 400 个克隆进行测序, 最后获得 70 个属于不同种类超微 型真核生物的 OTU ${ }^{[23]}$. 这些研究均获得了丰富的超微型真核生物多样性, 表明克隆文库构建方法适用于本 研究,为我们客观认识环境中真核生物多样性提供途径. 但构建克隆文库直接测序耗时且花费较大.

DGGE 是检测微生物多样性的一种快速可靠的方法, 其带谱中条带的数量和亮度可相应地反映环境样 品中微生物物种的数量和优势种群 ${ }^{[24]}$. 此方法的优点是可以同时对大量不同的环境样品比较分析, 缺点是 不知道样品中具体的生物组成 ${ }^{[25]}$. 而构建克隆文库, 通过测序及网上比对, 能够知道样品中主要的物种组成 与相对丰度. 结合两种方法, 能够扬长避短, 即可对不同时空的样品进行分析, 也可了解样品的主要物种组 成 ${ }^{[26]}$. 所以我们将结合这两种方法进一步研究太湖自养真核超微藻的遗传多样性.

本研究目前只对太湖 2010 年 3 月份 $\mathrm{T} 1$ 、 $\mathrm{T} 2$ 点的样品进行初次分析, 但可以推测湖泊中自养真核超微藻 具有复杂的遗传多样性. 我们将对太湖这些位点的水样进行进一步调查, 系统地研究太湖自养真核超微藻 的遗传多样性.

\section{2 太湖不同湖区自养真核超微藻的分布}

$\mathrm{T} 1$ 点位于太湖污染最为严重的梅梁湾, $\mathrm{T} 2$ 点位于水质相对最好的东太湖, 本文以这两个富营养化程度 相差较大的湖区作为代表来反映太湖不同湖区自养真核超微藻的分布情况. 结果表明 $\mathrm{T} 1$ 、 $\mathrm{T} 2$ 点均有隐藻和 硅藻, 可见春季隐藻与硅藻分布较为广泛, 可能在太湖的其他湖区也存在. 其中优势种群为隐藻, 说明隐藻 适应性强,生长旺盛. 金藻多生活在透明度高, 有机质含量低的水体中 ${ }^{[27]}$, 东太湖金藻的发现, 验证了东太湖 水质相对较好, 能够为金藻的生长提供适宜的环境. 已发现的定鞭藻主要存在于海洋中, 在淡水生态系统中 很少 ${ }^{[28]}$. 太湖梅梁湾发现定鞭藻, 说明定鞭藻的生境可能比以往认识得更为广泛, 还可存在于富营养化的湖 泊中. 本研究得到的序列经比对后发现很多未培养、系统分类未定的藻类, 说明我们对于真核超微藻的研究 还很有限, 需要进一步加深对其的认识.

\section{4 参考文献}

[ 1 ] Vaulot D, Eikrem W, Viprey M et al. The diversity of small eukaryotic phytoplankton $(\leqslant 3 \mu \mathrm{m})$ in marine ecosystems. FEMS Microbial Review, 2008, 32: 795-820.

[ 2 ] Platt T, Subba-Rao DV, Erwin B. Photosynthesis of picoplankton in the oligotrophic ocean. Nature, 1983, 301 : 702-704.

[ 3 ] Li WKW. Primary productivity of prochlorophytes, cyanobacteria, and eukaryotic ultraphytoplankton: measurements from flow cytometric sorting. Limnology and Oceanography, 1994, 39: 169-175.

[ 4 ] Šlapeta J, Moreira D, López-García P. The extent of protist diversity: insights from molecular ecology of freshwater eukaryotes. Proceedings of the Royal Society B, 2005, 272 : 2073-2081.

[ 5 ] Richards TA, Vepritskiy AA, Gouliamova DE et al. The molecular diversity of freshwater picoeukaryotes from an oligotrophic lake reveals diverse, distinctive and globally dispersed lineage. Environmental Microbiology, 2005, 7: 1413-1425.

[6] 陈纪新, 黄邦钦, 李少菁. 海洋微型浮游植物分子生态学研究进展. 厦门大学学报: 自然科学版, 2006, 45: 32-39.

[7] 袁 洁, 邵 鹏, 陈月琴等. 南沙群岛微型与超微型真核藻类遗传多样性的初步研究. 海洋科学, 2003, 27(7): 43-47.

[8] 王 建, 林婉莲. 武汉东湖超微藻生态学的初步研究. 湖泊科学, 1998, 10(4): 71-75.

[ 9 ] 陈美军, 孔繁翔, 陈非洲等. 太湖不同湖区真核微型浮游生物基因多样性的研究. 环境科学, 2008, 29(3): 769-774.

[10] Chen MJ, Chen FZ, Zhao BY et al. Spatio-temporal variability of microbial eukaryotic community composition in a large shallow subtropical lake, assessed by $18 \mathrm{~S}$ rRNA gene sequences. Acta Protozoologica, 2009, 48(3) : 245-264.

[11] Chen MJ, Chen FZ, Yu Y et al. Genetic diversity of eukaryotic microorganisms in Lake Taihu, a large shallow subtropical 
lake in China. Microbial Ecology, 2008, 56(3) : 572-583.

[12] Moon-van der Staay SY, Georg WM, Guillou L et al. Abundance and diversity of prymnesiophytes in the picoplankton community from the equatorial Pacific Ocean inferred from 18S rDNA sequences. Limnology and Oceanography, 2000, 45: 98-109.

[13] Not F, Latasa M, Marie D et al. A single species, Micromonas pusilla (Prasinophyceae), dominates the eukaryotic picoplankton in the western English channel. Applied and Environmental Microbiology, 2004, 70 : 4064-4072.

[14] Fuller NJ, Campbell C, Allen DJ et al. Analysis of photosynthetic picoeukaryote diversity at open ocean sites in the Arabian Sea using a PCR biased towards marine algal plastids. Aquatic Microbial Ecology, 2006, 43 : 79-93.

[15] Khadidja R, Daniel V. Compositon and temporal variability of picoeukaryote communities at a coastal site of the English Channel from 18S rDNA sequences. Limnology and Oceanography, 2004, 49:784-798.

[16] McDonald SM, Sarno D, Scanlan DJ et al. Genetic diversity of eukaryotic ultraphytoplankton in the Gulf of Naples during an annual cycle. Aquatic Microbial Ecology, 2007, 50:75-89.

[17] Bruckner CG, Bahulikar R, Rahalkar M et al. Bacteria associated with benthic diatoms from Lake Constance: phylogeny and influences on diatom growth and secretion of extracellular polymeric substances. Applied and Environmental Microbiolo$g y, 2008, \mathbf{7 4}(24):$ 7740-7749.

[18] Stein LY, Jones G, Alexander B et al. Intriguing microbial diversity associated with metal-rich particles from a freshwater reservoir. FEMS Microbiology Ecology, 2002, 42(3):431-440.

[19] Sieburth JM, Smetacek V, Lenz J. Pelagic ecosystem structure: Heterotrophic compartments and their relationship to plankton size fractions. Limnology and Oceanography, 1978, 23 : 1256-1263.

[20 Moon-van der Staay SY, Wachter RD, Vaulot D. Oceanic 18S rDNA sequences from picoplankton reveal unsuspected eukaryotic diversity. Nature, 2001, 409: 607-610.

[21] Worden AZ. Picoeukaryote diversity in coastal waters of the Pacific Ocean. Aquatic Microbial Ecology, 2006, 43 : 165-175.

[22] Soo-Je P, Byoung-Joon P, Vinh HP et al. Microeukaryotic diversity in marine environments, an analysis of surface layer sediments from the East Sea. The Journal of Microbiology, 2008, 46(3) : 44-49.

[23] Zuendorf A, Bunge J, Behnke A et al. Diversity estimates of microeukaryotes below the chemocline of the anoxic Mariager Fjord, Denmark. FEMS Microbiology Ecology, 2006, 58: 476-491.

[24] Fromin N, Hamelin J, Tarnawaski S et al. Statistical analysis of denaturing gel electrophoresis(DGE) fingerprinting patterns. Environmental Microbiology, 2002, 4(11): 634-643.

[25] Gast RJ, Dennett MR, Caron DA. Characterization of protistan assemblages in the Ross Sea, Antarctica, by denaturing gradient gel electrophoresis. Applied and Environmental Microbiology, 2004, 70(4) : 2028-2037.

[26] Stocek T, Hayward B, Taylor GT et al. Amultiple PCR-primer approach to access the microeukaryote diversity in environmental samples. Protist, 2006, 157: 31-43.

[27] Nieholls KH, Wujek DE. Freshwater algae of North America. USA: Elsevier Science, 2003: 471-509.

[28 ] Bente E, Wenche E, Green JC et al. Phylogenetic reconstructions of the Haptophyta inferred 18S ribosomal DNA sequences and available morphological data. Phycologia , 2000, 39(1) : 19-35. 